gabapentin, lamotrogine, and other newer agents during pregnancy is relatively sparse, but teratogenicity has not been reported.

\title{
GROWTH SUPPRESSION WITH ACETAZOLAMIDE
}

The effect of acetazolamide on growth of children with epilepsy was evaluated at Osaka Medical Center, Japan. Standard scores of height and weight were compared in 17 children receiving acetazolamide as an adjunct to AED monotherapy: 1) before AED treatment; 2) during AED monotherapy; 3) during adjunct acetazolamide therapy; and 4) after acetazolamide had been discontinued. Both height and weight were significantly reduced during acetazolamide administration, and growth returned to the original level after acetazolamide was withdrawn. The degree of growth suppression was not related to the age, duration, dosage, or the concomitant AED therapy. Metabolic acidosis induced by acetazolamide was postulated as the cause. (Futagi Y, Otani $\mathrm{K}$, Abe J. Growth suppression in children receiving acetazolamide with antiepileptic drugs. Pediatr Neurol Nov 1996;15:323-326). (Respond: Dr Futagi, Division of Pediatric Neurology, Osaka Medical Center and Research Institute, 840 Murodo-cho, Izumi, Osaka 590-02, Japan).

COMMENT: Anorexia and loss of weight have been reported with acetazolamide therapy for epilepsy (Millichap et al. 1956, 1964), but this seems to be the first report of acetazolamide-induced growth suppression. Height and weight should be monitored carefully during acetazolamide therapy.

Since the metabolic side effects of the ketogenic diet are similar to those of acetazolamide (Millichap JG. Progress in Pediatric Neurology I, PNB Publ, 1991:pp85-88), and loss of weight is a common occurrence with the initiation of the diet, monitoring of height and weight are equally important during ketogenic dietary therapy. Two children under one year of age showed no increase in weight, length or head circumference during a six month period on the diet (Schwartz RH et al, 1989), and the monitoring of acetazolamide or the ketogenic diet in infants and young children should be especially strict.

\section{ATTENTION DEFICIT DISORDERS}

\section{ADHD AND PSYCHOACTIVE SUBSTANCE ABUSE}

The effect of attention-deficit hyperactivity disorder (ADHD) compared to psychiatric comorbidity, familiality, and adversity, as risk factors for psychoactive substance use disorder (PSUD) was evaluated at the Department of Psychiatry, Massachusetts General Hospital, Boston, MA. Using baseline and 4year follow-up data from 140 ADHD and 120 normal control subjects, the rates of alcohol or drug abuse or dependence (PSUD) were $15 \%$, with no differences between groups. Conduct and bipolar disorders were predictive of PSUD, but these associations were independent of ADHD. Oppositional defiant disorder, uncomplicated by conduct disorder, did not predict PSUD. Family history of substance dependence and antisocial disorders was associated with PSUD in controls but less so in ADHD probands. Family history of ADHD was not associated with risk of PSUD. (Biederman J, Wilens T, Mick E et al. Is ADHD a risk factor for psychoactive substance use disorders? Findings from a fouryear prospective follow-up study. L Am Acad Child Adolesc Psychiatry Jan 1997;36:21-29). (Reprints: Dr Biederman, Pediatric Psychopharmacology Unit (ACC 725), Massachusetts General Hospital, Fruit Street, Boston, MA 02114). 
COMMENT. Adolescents with or without ADHD have a similar risk of psychoactive substance use disorders (PSUD), with a frequency of $15 \%$. However, children with ADHD may be at higher risk for early-onset addictions than controls. PSUD in adolescents is associated with a history of conduct and bipolar disorders, but not oppositional defiant disorder, major depression, or anxiety disorders. The risk of PSUD is increased in adults with ADHD, and a sharp increase in PSUD may be expected in adolescent ADHD subjects as they become adults.

Comorbid ADHD and substance abuse. Comorbidity of ADHD among adolescents in treatment for substance abuse is reported from the National Center for Post Traumatic Stress Disorder, Veteran's Affairs Medical Center, West Haven, CT. (Horner BR, Scheibe KE. Prevalence and implications of attention-deficit hyperactivity disorder among adolescents in treatment for substance abuse. L Am Acad Child Adolesc Psychiatry Jan 1997;36:30-36). Attempts to self-medicate symptoms of ADHD may underlie substance use and abuse, especially in previously untreated adolescents. Prescribed medical treatment for ADHD may decrease drug craving in adults with ADHD and improve functioning.

ADHD and cigarette smoking. ADHD, particularly when associated with conduct disorders, is a significant risk factor for early cigarette smoking in children and adolescents in a study at the Massachusetts General Hospital, Boston. (Milberger S, Biederman J, Faraone SV, Chen L, Jones J. ADHD is associated with early initiation of cigarette smoking in children and adolescents. IAm Acad Child Adolesc Psychiatry Jan 1997;36:37-44).

\section{ADHD AND MOTOR VEHICLE SKILIS AND RISKS}

The motor vehicle skills, risks, and accidents in 25 young adults with ADHD were compared with 23 non-ADHD adult control subjects, aged 17 to 30 years, at the Departments of Psychiatry and Neurology, University of Massachusetts Medical Center, Worcester, MA. ADHD young adults were twice as likely to be cited for unlawful speeding, had more crashes, more accidents involving bodily injury, more likely to have licenses suspended, and poorer driving habits and performance despite adequate driving knowledge, when compared to controls. (Barkley RA, Murphy KR, Kwasnik D. Motor vehicle driving competencies and risks in teens and young adults with attention deficit hyperactivity disorder. Pediatrics Dec 1996;98:1089-1095). (Reprints: Russell A Barkley PhD, Department of Psychiatry, University of Massachusetts Medical Center, 55 Lake Ave North, Worcester, MA 01655).

COMMENT. This study confirms previous reports of an increased risk of motor vehicle accidents and injury among ADHD young adults. The findings indicate the need for continued treatment and supervision of adolescents with ADHD into adulthood, particularly in relation to self-regulation of motor control and lessening of impulsive behavior.

\section{METHYLPHENIDATE USAGE FOR ADHD IN THE 1990s}

The usage and usage trends for methylphenidate (MPH) treatment of ADHD from 1990 through 1995 were estimated by the Departments of Psychiatry and Pediatrics, Johs Hopkins University School of Medicine, Baltimore County Health Department, and the Schools of Pharmacy and Medicine, University of Maryland, Baltimore, MD. A review of regional and national databases showed a 2.5 -fold increase in the prevalence of MPH treatment of youths with $\mathrm{ADD}$ in this time period. Approximately $2.8 \%(1.5$ 